\title{
Effect of Recombinant Human Erythropoietin in a Rat Model of Moderate Chronic Renal Failure - Focus on Inflammation, Oxidative Stress and Function/Renoprotection
}

\author{
P. Garrido ${ }^{*}, 1$, F. Reis ${ }^{1,3}$, E. Costa ${ }^{2,3}$, A. Almeida ${ }^{4}$, B. Parada ${ }^{1,5}$, E. Teixeira-Lemos ${ }^{1}$, P. Santos ${ }^{4}$, R. Alves ${ }^{6}$, \\ J. Sereno $^{1}$, R. Pinto ${ }^{7}$, C.A. Tavares ${ }^{8}$, A. Figueiredo ${ }^{1,5}$, P. Rocha-Pereira ${ }^{9}$, L. Belo ${ }^{3,10}$, A. Santos-Silva ${ }^{3,10}$ \\ and F. Teixeira ${ }^{*}, 1,3$ \\ ${ }^{I}$ Institute of Pharmacology \& Experimental Therapeutics, IBILI, Medicine Faculty, Coimbra University, Portugal \\ ${ }^{2}$ Institute of Health Sciences of University Catholic, Porto, Portugal \\ ${ }^{3}$ Institute for Molecular and Cellular Biology, Porto University, Portugal \\ ${ }^{4}$ Functional Genomics Laboratory, Center of Histocompatibility of the Centre, Coimbra, Portugal \\ ${ }^{5}$ Service of Urology and Renal Transplantation, HUC, Portugal \\ ${ }^{6}$ Department of Nephrology, Medicine Faculty, Coimbra University Portugal \\ ${ }^{7}$ Pharmacology and Pharmacotoxicology Unit, Pharmacy School, University of Lisbon \\ ${ }^{8}$ Laboratory of Hematology, HUC, Portugal \\ ${ }^{9}$ Research Centre for Health Sciences, Beira Interior University, Covilhã, Portugal \\ ${ }^{10}$ Biochemistry Department, Pharmacy Faculty, Porto University, Portugal
}

\begin{abstract}
Background/Aims: Chronic renal failure (CRF) patients develop anaemia, thus promoting cardiovascular complications, which seems to be favoured by the low kidney erythropoietin (EPO) production. The renal insufficiency degree might determine the moment to start recombinant human EPO (rhEPO) therapy. It has been attributed important non-hematopoietic effects to rhEPO, which might underlie cardio and renoprotection. This work aimed to evaluate the effect of rhEPO in a rat model of moderate CRF, focusing on inflammation, oxidative stress and function/renoprotection.

Methods: Four groups $(\mathrm{n}=7)$ of male Wistar rats were evaluated during a 15 week follow-up period: control (without treatment); rhEPO (50 IU/Kg/wk Recormon ${ }^{\mathbb{B}}$ ); CRF and CRF+rhEPO. Blood samples were collected at the beginning and 3, 9 and 12 weeks after $3 / 4$ nephrectomy, in order to evaluate: renal function, haematological parameters, iron metabolism and serum proliferative (TGF- $\beta 1$ ), inflammatory (TNF- $\alpha$, CRP, IL-2 and IL-1 $\beta$ ) and redox status (MDA, TAS and 3-NT) markers. Kidney gene expression of I12, Vegf, Nos2 and Nos3 were assessed by real-time PCR. Blood pressure, heart rate and tissues trophy indexes were also estimated.

Results: Our data are consistent with a sustained moderate degree of CRF with development of moderate and corrected anaemia and hypertension. The remnant kidney showed a proliferative profile, with increased mass (hypertrophism), upregulated tissue Vegf gene expression, accompanied by increased levels of serum TGF- $\beta 1$. Serum 3-NT was augmented, suggesting oxidative stress, which was accompanied by a trend to higher kidney Nos gene expression of both isoforms. rhEPO treatment was able to partially attenuate renal function markers, totally correct anaemia, also demonstrating a proliferative and antioxidant action, suggesting renoprotection.

Conclusion: This study suggests that rhEPO therapy might be recommended in moderate CRF stages in order to efficiently correct not only the anaemia but also the underlying deleterious mechanisms, due to a proliferative and antioxidant action on the remnant kidney.
\end{abstract}

Keywords: Moderate chronic renal failure, erythropoietin treatment, renoprotection, proliferation, inflammation, oxidative stress.

*Address correspondence to these authors at the Institute of Pharmacology and Experimental Therapeutics, Medicine Faculty, Sub-Unit 1 (Pólo III), Coimbra University, 3000-354 Coimbra, Portugal; Tel: +351 239 480068; Fax: +351 239 480073;

E-mails: fredjt@ci.uc.pt, apatricia.garrido@gmail.com

\section{INTRODUCTION}

Anaemia is a frequent complication associated with renal failure, and is mainly due to insufficient erythropoietin renal production. Accumulation of uremic toxins, excessive toxic storage of aluminium in the bone marrow [1], blood loss, and premature erythrocyte destruction have been also frequently 
associated with anaemia of renal failure patients $[2,3]$. This anaemia develops gradually, with the progressive decline of renal function [4-6] and EPO synthesis [4, 6]. Anaemia can lead to adverse clinical effects, namely, reduction in tissue oxygenation, increase in cardiac output, left ventricular hypertrophy, congestive heart disease, fatigue, reduction in exercise capacity, and immunodeficiency [7, 8].

Until 18 years ago, the treatment of anaemia of renal failure was blood transfusion; since there, the management of this anaemia has been improved by the introduction of recombinant human erythropoietin (rhEPO) therapy. This therapy allowed a significant reduction in the associated adverse effects of anaemia and improved patient's quality of life.

Currently, the main indication for rhEPO is the treatment of anaemia. However, an increasingly growing body of evidence indicates that therapeutic benefits of rhEPO could be far beyond correction of anaemia, namely in cardiovascular and nervous systems [9-11]. In fact, considering the wide distribution of erythropoietin receptor (EPOR) expression in body cells and tissues [12], it would be surprising if no effect were observed outside the erythroid cells. EPOR are also present in kidney tissue, especially on tubular cells [13]. It has been described that EPO activates different intracellular pathways in kidney tissue such as the PI3K/Akt pathway, a signalling pathway pivotal for cell survival, suggesting that administration of rhEPO could have also a protective effect in acute renal failure, such as ischemic injury, and in moderate stages of renal failure, contributing to organ protection/regeneration [14-16].

The non-hematopoietic effects currently attributed to rhEPO therapy, known as a pleiotrophic action, might include and be important for a better cardio and renoprotection. This potential erythropoietin protective mechanism might be associated with a regenerative/ proliferative cell effect, and/or with anti-inflammatory and antioxidant properties. The aim of this work was to evaluate these potential rhEPO effects by studying inflammatory and redox status markers, as well as markers of renal function/renoprotection, by using a rat model of moderate renal failure induced by partial (3/4) nephrectomy, along a 15 week protocol study.

\section{MATERIAL AND METHODS}

\section{Animals and Experimental Protocol}

Male Wistar rats (Charles River Lab. Inc., Barcelona, Spain), 250-300g, were maintained in an air conditioned room, subjected to 12-h dark/light cycles and given standard laboratory rat diet (IPM-R20, Letica, Barcelona, Spain) and free access to tap water. Animal experiments were conducted according to the European Communities Council Directives on Animal Care.

The rats were divided into 4 groups (7 rats each): a control, without drugs and surgery; a rhEPO (beta) group, treated with 50 IU/Kg/week Recormon ${ }^{\circledR}$ (Roche Pharmaceuticals); a group with surgical CRF induced by a two-stage (3/4) nephrectomy: firstly, about half of the left kidney was removed by left flank incision and, one week later, the right kidney was removed through a right lateral flank incision; and at last a CRF+rhEPO group, which was treated with rhEPO after the $3^{\text {rd }}$ week of surgery All the animals have completed the 15-week protocol. Body weight (BW) was monitored during the study and blood pressure (BP) and heart rate (HR) measures using a tail-cuff sphygmomanometer LE 5001 (Letica, Barcelona, Spain).

\section{Sample Collection and Preparation}

Blood: At the beginning of the experiments and at 3,9 and 12 weeks after the surgical partial nephrectomy the rats were subjected to intraperitoneal anesthesia with a $2 \mathrm{mg} / \mathrm{kg}$ BW of a 2:1 (v:v) $50 \mathrm{mg} / \mathrm{mL}$ ketamine (Ketalar ${ }^{\circledR}$, ParkeDavis, Lab. Pfeizer Lda, Seixal, Portugal) solution in $2.5 \%$ chlorpromazine (Largactil $^{\circledR}$, Rhône-Poulenc Rorer, Lab. Vitória, Amadora, Portugal). Blood samples were immediately collected by venipuncture from the jugular vein into syringes without anticoagulant (for serum sample collection) or with EDTA for haematological studies.

Tissues: The rats were sacrificed by cervical dislocation and the heart and kidneys were immediately removed, placed in ice-cold Krebs' buffer and carefully cleaned of adherent fat and connective tissue. The BW, the whole heart weight (HW), the left ventricle weight (LVW) and the kidney weight $(\mathrm{KW})$ were measured in order to be used as trophy indexes.

\section{Biochemical and Haematological Assays}

Renal Function: Serum creatinine, ureia and uric acid concentrations were used as renal function indexes through automatic validated methods and equipments (Hitachi 717 analyser).

Haematological Data: Red blood cell (RBC) count, haematocrit, haemoglobin $(\mathrm{Hb})$ concentration, haematological indices [mean cell volume (MCV), mean cell $\mathrm{Hb}$ $(\mathrm{MCH})$ and mean cell $\mathrm{Hb}$ concentration $(\mathrm{MCHC})]$, red cell distribution width (RDW), reticulocyte count, immature reticulocyte fraction (IRF), platelets and white blood cell (WBC) counts were assessed in whole blood EDTA by using an automatic Coulter Counter ${ }^{\circledR}$ (Beckman Coulter Inc., USA, CA).

Iron Metabolism: Serum iron concentration was determined using a colorimetric method (Iron, Randox Laboratories Ltd., North Ireland, UK), whereas serum ferritin and transferrin were measured by immunoturbidimetry (Laboratories Ltd., North Ireland, UK).

\section{Inflammatory Markers and Redox Status}

Serum levels of interleukin 2 (IL-2), IL-1 $\beta$, transforming growth factor $\beta 1$ (TGF- $\beta 1$ ) and tumour necrosis factor $\alpha$ $\left(\right.$ TNF- $\alpha$ ) were measured by ultrasensitive Quantikine ${ }^{\circledR}$ ELISA kits (R\&D Systems, Minneapolis, USA). Serum Creactive protein (CRP) was determined by using an ELISA kit from Helica Biosystems, Inc. (Fullerton, CA, USA). All assays were performed in duplicate.

The thiobarbituric acid reactive-species (TBARs) assay was used to assess serum products of lipid peroxidation, namely malondialdehyde (MDA) [17]. Ferric reducing antioxidant potential (FRAP) assay was used to estimate serum total antioxidant status (TAS) [18]. Serum 3nitrotyrosine (3-NT), which is an index of peroxynitrite 
formation, was measured by immunoassay (HyCult biotechnology b.v., Uden, Netherlands).

\section{Gene Expression Analysis}

Total RNA Isolation: Kidneys were isolated in autopsy and stored in RNA later ${ }^{\mathrm{TM}}$ solution (Ambion, Austin, USA). Samples were removed from preservation solution and 1200 $\mu 1$ of RLT Lysis Buffer were added to proceed with disruption and homogenization for 2 minutes at $30 \mathrm{~Hz}$ using TissueLyser (Qiagen, Hilden, Germany). Thirty milligrams of tissue lysate were processed according to the protocol from RNeasy ${ }^{\circledR}$ Mini Kit (Qiagen, Hilden, Germany) for Isolation of Total RNA extraction from animal tissues and total RNA was eluted in $50 \mu 1$ of RNase-free water (without optional treatment with DNAse). In order to quantify the amount of total RNA extracted and verify RNA integrity (RIN, RNA Integrity Number), samples were analyzed using 6000 Nano Chip ${ }^{\circledR}$ kit, in Agilent 2100 bioanalyzer (Agilent Technologies, Walbronn, Germany) and 2100 expert software, following manufacturer instructions. The yield from isolation was from 0.5 to $3 \mu \mathrm{g}$; RIN values were 6.0-9.0 and purity $\left(\mathrm{A}_{260} / \mathrm{A}_{280}\right)$ was 1.8-2.0.

Reverse Transcription: RNA was reverse transcribed with SuperScript ${ }^{\mathrm{TM}}$ III First-Strand Synthesis System for RTPCR (Invitrogen, California, USA). One microgram of total RNA was mixed with a 2X First-Strand Reaction Mix (Oligo(dT) plus Random hexamers) and a SuperScript ${ }^{\mathrm{TM}}$ III Enzyme Mix, according to manufacturer instructions. Reactions were carried out in a thermocycler Gene Amp PCR System 9600 (Perkin Elmer, Norwalk, USA), 10 min at $25^{\circ} \mathrm{C}, 50 \mathrm{~min}$ at $50^{\circ} \mathrm{C}$ and $5 \mathrm{~min}$ at $85^{\circ} \mathrm{C}$. Reaction products were then digested with $1 \mu 1 \mathrm{RNase} \mathrm{H}$ for $20 \mathrm{~min}$ at $37^{\circ} \mathrm{C}$ and, finally, cDNA eluted to a final volume of $100 \mu \mathrm{l}$ and stored at $-20^{\circ} \mathrm{C}$.

Relative Quantification of Gene Expression: Relative quantification of gene expression by real-time PCR was performed using 7900 HT Sequence Detection System (Applied Biosystems, Foster City, USA). A normalization step preceded the gene expression quantification, using geNorm Housekeeping Gene Selection kit for Rattus norvegicus (Primer Design, Southampton, United Kingdom) and geNorm software (Ghent University Hospital, Center for Medical Genetics, Ghent, Belgium) to select optimal housekeeping genes to this study [19].
Real-time PCR reactions used optimized specific primers (Proligo, Boulder, USA) for genes of interest Nos2, Nos3, Vegf and I12 and endogenous controls Actb, Gapdh, Top1 (Table 1) together with QuantiTect SYBR Green PCR Kit Gene expression. Real-time PCR reactions were carried out with: 100ng cDNA sample, primers $(50-200 \mathrm{nM})$ and $1 \mathrm{X}$ QuantiTect SYBR Green PCR Master Mix. Non template control reactions were performed for each gene, in order to assure no unspecific amplification. Reactions were performed with the following thermal profile: 10 minutes at $95^{\circ} \mathrm{C}$ plus 40 cycles of 15 seconds at $95^{\circ} \mathrm{C}$ and 1 minute at $60^{\circ} \mathrm{C}$. Real-time PCR results were analyzed with SDS 2.1 software (Applied Biosystems, Foster City, USA) and quantification used the $2^{-\Delta \Delta \mathrm{Ct}}$ method [20]. Mann-Whitney U test was computed in SPSS 15.0 (SPSS Inc., Chicago, USA) to test differences between groups $(\mathrm{p}<0.05)$.

\section{Data Analysis}

For statistical analysis, we used the Statview 4.53 software from Abacus Concepts Inc. (Berkeley, CA, USA). Results are presented as mean \pm s.e.m. Comparisons between groups and different times were performed using one-way ANOVA and Fisher's test. Significance was accepted at $p$ less than 0.05 .

\section{RESULTS}

We analysed the results in two ways, one to evaluate the changes imposed by rhEPO treatment and by nephrectomyinduced renal failure (rhEPO and CRF groups vs control); and the other to evaluate the changes induced by rhEPO treatment in CRF rats (rhEPO+CRF vs control).

\section{Biochemical and Haematological Data}

In Table $\mathbf{2}$ we present the renal function markers, haematological data and iron metabolism, for the different groups, before starting experiments and at the end of the experimental period (15 weeks: 12 weeks after partial nephrectomy). There was a statistically significant increase in serum creatinine and urea concentrations at the three weeks after surgery (data not shown), and this increase in renal function markers remained high along the following 12 weeks of the experimental procedure. The rhEPO treatment in the CRF animals produced no significant effects in those parameters (Table 2).

Table 1. Genes of Interest and Endogenous Controls Used in the Present RT-qPCR Study (Gene Symbol, Name, GenBank Number and Primers Sequences)

\begin{tabular}{|ccccc|}
\hline $\begin{array}{c}\text { Gene } \\
\text { Symbol }\end{array}$ & Gene Name & $\begin{array}{c}\text { GenBank } \\
\text { Number }\end{array}$ & $\begin{array}{c}\text { Forward Primer Sequence } \\
\text { (5'-3') }\end{array}$ & $\begin{array}{c}\text { Reverse Primer } \\
\text { Sequence (5'-3') }\end{array}$ \\
\hline \hline Length (bp)
\end{tabular}


Table 2. Effects of rhEPO Treatment in Renal Function, Hematological Data and Iron Metabolism in a Rat Model of Moderate CRF

\begin{tabular}{|c|c|c|c|c|c|}
\hline \multirow{3}{*}{ Parameters } & \multirow{3}{*}{$\begin{array}{c}\text { Initial Time }(0 \text { Weeks) } \\
\text { Before } 3 / 4 \mathrm{~N} \\
\text { All the Rats }\end{array}$} & \multicolumn{4}{|c|}{ Final Time (15 Weeks) } \\
\hline & & \multicolumn{2}{|c|}{ Without $3 / 4 \mathrm{~N}$} & \multicolumn{2}{|c|}{ With $3 / 4 \mathrm{~N}$} \\
\hline & & Controls & rhEPO & CRF & CRF+rhEPO \\
\hline \multicolumn{6}{|l|}{ Renal Function } \\
\hline Creatinine $(\mu \mathrm{mol} / \mathrm{L})$ & $36.24 \pm 1.78$ & $39.78 \pm 1.77$ & $38.90 \pm 2.64$ & $80.44 \pm 5.30^{\text {aа }}$ & $64.53 \pm 2.65$ \\
\hline Urea $(\mathrm{mmol} / \mathrm{L})$ & $14.63 \pm 0.24$ & $13.93 \pm 0.56$ & $13.78 \pm 0.61$ & $24.21 \pm 1.01^{\mathrm{a}}$ & $22.49 \pm 0.99$ \\
\hline Uric acid $(\mu \mathrm{mol} / \mathrm{L})$ & $35.69 \pm 3.57$ & $36.88 \pm 9.52$ & $49.37 \pm 8.33$ & $28.55 \pm 5.35$ & $36.88 \pm 5.95$ \\
\hline \multicolumn{6}{|l|}{ Haematological Data } \\
\hline $\mathrm{Hb}(\mathrm{g} / \mathrm{L})$ & $138.21 \pm 1.42$ & $139.44 \pm 3.61$ & $128.72 \pm 5.29$ & $134.39 \pm 2.01$ & $148.81 \pm 17.20$ \\
\hline Haematocrit $(\mathrm{L} / \mathrm{L})$ & $0.395 \pm 0.005$ & $0.409 \pm 0.007$ & $0.361 \pm 0.017$ & $0.395 \pm 0.006$ & $0.439 \pm 0.056$ \\
\hline $\operatorname{RBC}\left(\times 10^{12} / \mathrm{L}\right)$ & $7.32 \pm 0.12$ & $7.44 \pm 0.10$ & $6.84 \pm 0.38$ & $6.91 \pm 0.14$ & $7.83 \pm 0.94$ \\
\hline $\mathrm{MCV}(\mathrm{fL})$ & $53.95 \pm 0.62$ & $55.04 \pm 1.32$ & $53.08 \pm 0.73$ & $57.27 \pm 0.66$ & $55.75 \pm 0.78$ \\
\hline $\mathrm{MCH}(\mathrm{pg})$ & $18.85 \pm 0.25$ & $18.74 \pm 0.61$ & $18.90 \pm 0.30$ & $19.48 \pm 0.28$ & $19.06 \pm 0.21$ \\
\hline $\mathrm{MCHC}(\mathrm{g} / \mathrm{dL})$ & $34.93 \pm 0.19$ & $34.04 \pm 0.37$ & $35.60 \pm 0.21^{\text {aaa }}$ & $34.00 \pm 0.30$ & $34.21 \pm 0.47$ \\
\hline RDW (\%) & $13.3 \pm 0.4$ & $14.9 \pm 0.4$ & $15.3 \pm 0.7$ & $13.5 \pm 0.2$ & $15.2 \pm 1.2$ \\
\hline Reticulocytes $\left(\times 10^{9} / \mathrm{L}\right)$ & $389.01 \pm 29.10$ & $383.98 \pm 28.97$ & $286.04 \pm 22.01$ & $326.09 \pm 27.02$ & $228.08 \pm 17.98$ \\
\hline $\operatorname{IRF}(\%)$ & $0.38 \pm 0.02$ & $0.38 \pm 0.01$ & $0.41 \pm 0.02$ & $0.56 \pm 0.09$ & $0.42 \pm 0.07$ \\
\hline Platelets $\left(\times 10^{9} / \mathrm{L}\right)$ & $980.50 \pm 22.79$ & $980.40 \pm 33.07$ & $1007.00 \pm 56.85$ & $943.85 \pm 78.49$ & $888.66 \pm 90.17$ \\
\hline WBC $\left(\times 10^{9} / \mathrm{L}\right)$ & $6.87 \pm 1.19$ & $5.14 \pm 0.22$ & $2.27 \pm 1.07^{\mathrm{a}}$ & $5.53 \pm 0.85$ & $5.05 \pm 0.91$ \\
\hline \multicolumn{6}{|l|}{ Iron Metabolism } \\
\hline Iron $(\mu \mathrm{mol} / \mathrm{L})$ & $27.42 \pm 2.31$ & $27.60 \pm 4.82$ & $29.09 \pm 1.35$ & $22.29 \pm 2.13$ & $21.05 \pm 4.10$ \\
\hline Ferritin (pmol/L) & $28.38 \pm 3.03$ & $29.03 \pm 8.27$ & $408.19 \pm 29.62^{\text {аaа }}$ & $55.41 \pm 11.95^{\mathrm{a}}$ & $267.62 \pm 7.86^{\mathrm{bbb}}$ \\
\hline Transferrin $(g / L)$ & $1.30 \pm 0.04$ & $1.20 \pm 0.08$ & $1.22 \pm 0.03$ & $0.81 \pm 0.11^{\text {aaa }}$ & $0.98 \pm 0.12$ \\
\hline
\end{tabular}

$\mathrm{N}$ : nephrectomy. Results are mean \pm s.e.m. of 7 rats for each group: a $-p<0.05$, aa $-p<0.01$ and aaa $-p<0.001 v s$ the control group; $\mathrm{b}-p<0.05$, bb - $p<0.01$ and bbb- $p<0.001 v s$ the CRF group.

Concerning to haematological data, 3 weeks after nephrectomy, the CRF animals showed a statistically significant decrease for RBC count, $\mathrm{HTC}$ and $\mathrm{Hb}$, alongside with a significantly increase in platelet count and RDW (data not shown). These parameters normalized in the laboratorial evaluation performed 9 weeks after surgical intervention and remained stables until the end of the follow-up period. No statistically significant differences were found for total WBC counts. The rhEPO treatment in the CRF animals $(\mathrm{CRF}+\mathrm{rhEPO}$ group) showed a trend to increased haematological values (RBC, HTC and $\mathrm{Hb}$ ) (Table 2).

The evaluation of iron metabolism in CRF rats, showed no alterations in iron serum levels, a progressively increase in ferritin content, which reached statistical significance at 15 weeks (12 weeks after surgery). On the contrary, at the end of the follow-up period, transferrin serum levels were significantly lower in CRF animals than those of the control rats (Table 2). Furthermore, the treatment of CRF rats with rhEPO produced no effects in iron serum levels, but increased significantly ferritin, when compared with the CRF group. In addition, the transferrin levels were higher in $\mathrm{CRF}+\mathrm{rhEPO}$ rats than in CRF animals, but without statistical significance (Table 2).

\section{Blood Pressure, Heart Rate and Tissue Trophy Indexes}

A statistically significant increase in SBP, DBP, MBP and HR were also found in CRF rats, together with an increase in heart and left ventricle weights, and without differences in the tissue trophy indexes (Table 3 ). The rats only treated with rhEPO have significantly increased the SBP, DBP, MBP and HR. The rhEPO treatment in the CRF rats $(\mathrm{CRF}+\mathrm{rhEPO}$ group) showed a trend to attenuate the blood pressure values and significantly $(\mathrm{P}<0.05)$ corrected HR values. This group (CRF+rhEPO) still showed a trend to increased values of kidney weight and $\mathrm{KW} / \mathrm{BW}$ tissue trophy index when compared with CRF group (Table 3 ).

\section{Inflammatory Markers and Redox Status}

Concerning inflammatory markers, no significant differences for CRP, IL- $1 \beta$, IL- 2 and TNF- $\alpha$ serum levels were observed, but an increased concentration of TGF- $\beta 1$ was found in the CRF rats $v s$ the control group. The rhEPO treatment of CRF rats produced no significant changes for CRP, IL-1 $\beta$, IL-2 and TNF- $\alpha$ serum concentration (CRF+rhEPO group), but imposed a further increase $(\mathrm{P}<0.01)$ in the TGF- $\beta 1$ value, found in the CRF animals (Table 3). 
Table 3. Effects of rhEPO Treatment on Blood Pressure, Heart Rate, Tissue Trophy Indexes and Inflammatory and Redox Status Markers in a Rat Model of Moderate CRF

\begin{tabular}{|c|c|c|c|c|}
\hline \multirow{3}{*}{ Parameters } & \multicolumn{4}{|c|}{ Final Time - 15 Weeks } \\
\hline & \multicolumn{2}{|c|}{ No Surgery } & \multicolumn{2}{|c|}{ With $3 / 4 \mathrm{~N}$} \\
\hline & Control & rhEPO & CRF & CRF+rhEPO \\
\hline \multicolumn{5}{|l|}{ Blood Pressures and HR } \\
\hline $\mathrm{SBP}(\mathrm{mmHg})$ & $114.88 \pm 3.08$ & $135.96 \pm 3.07^{\text {aaa }}$ & $143.07 \pm 4.61^{\text {aаa }}$ & $139.71 \pm 3.33$ \\
\hline $\mathrm{DBP}(\mathrm{mmHg})$ & $99.11 \pm 1.76$ & $109.55 \pm 4.51^{\mathrm{a}}$ & $123.31 \pm 12.38^{\text {aa }}$ & $113.21 \pm 0.96$ \\
\hline MBP (mmHg) & $104.33 \pm 1.89$ & $117.78 \pm 3.80^{\mathrm{aa}}$ & $129.64 \pm 9.79^{\text {aаa }}$ & $121.69 \pm 0.78$ \\
\hline HR (beats/min.) & $339.12 \pm 6.28$ & $380.00 \pm 2.56^{\text {aaa }}$ & $391.89 \pm 12.00^{\text {aаa }}$ & $357.40 \pm 2.88^{\mathrm{b}}$ \\
\hline \multicolumn{5}{|l|}{ Body and Tissue Weights } \\
\hline BW (Kg) & $0.47 \pm 0.02$ & $0.49 \pm 0.02$ & $0.46 \pm 0.01$ & $0.48 \pm 0.03$ \\
\hline HW (g) & $1.21 \pm 0.03$ & $1.37 \pm 0.11$ & $1.46 \pm 0.06^{\mathrm{a}}$ & $1.48 \pm 0,08$ \\
\hline LVW (g) & $0.57 \pm 0.03$ & $0.48 \pm 0.06$ & $0.72 \pm 0.04^{\mathrm{a}}$ & $0.71 \pm 0.04$ \\
\hline KW (g) & $1.24 \pm 0.04$ & $1.28 \pm 0.06$ & $1.94 \pm 0.20$ & $2.21 \pm 0.47$ \\
\hline \multicolumn{5}{|l|}{ Tissue Trophy Indexes } \\
\hline HW/BW (g/kg) & $2.65 \pm 0.07$ & $2.80 \pm 0.17$ & $2.98 \pm 0.10$ & $3.13 \pm 0.31$ \\
\hline LVW/HW (g/kg) & $0.47 \pm 0.02$ & $0.36 \pm 0.05^{\mathrm{a}}$ & $0.50 \pm 0.02$ & $0.48 \pm 0.02$ \\
\hline LVW/BW (g/kg) & $1.05 \pm 0.11$ & $0.98 \pm 0.10$ & $1.17 \pm 0.14$ & $1.36 \pm 0.20$ \\
\hline $\mathrm{KW} / \mathrm{BW}(\mathrm{g} / \mathrm{kg})$ & $2.62 \pm 0.05$ & $2.63 \pm 0.08$ & $3.96 \pm 0.39$ & $5.12 \pm 1.49$ \\
\hline \multicolumn{5}{|l|}{ Inflammatory Profile } \\
\hline $\mathrm{CRP}(\mu \mathrm{g} / \mathrm{ml})$ & $24.78 \pm 1.25$ & $24.47 \pm 0.90$ & $25.83 \pm 0.66$ & $26.93 \pm 0.98$ \\
\hline IL-1 $\beta(\mathrm{pg} / \mathrm{ml})$ & $26.52 \pm 0.94$ & $26.19 \pm 0.99$ & $23.76 \pm 0.99$ & $27.50 \pm 0.95$ \\
\hline IL-2 (pg/ml) & $36.28 \pm 8.70$ & $47.35 \pm 3.50$ & $49.34 \pm 3.43$ & $47.19 \pm 3.50$ \\
\hline TGF- $\beta 1$ (pg/ml) & $358.41 \pm 34.52$ & $395.91 \pm 21.56$ & $544.42 \pm 50.43^{\mathrm{a}}$ & $734.47 \pm 30.99^{b}$ \\
\hline TNF- $\alpha(\mathrm{pg} / \mathrm{ml})$ & $16.34 \pm 1.81$ & $17.56 \pm 2.12$ & $15.75 \pm 1.96$ & $19.85 \pm 2.44$ \\
\hline \multicolumn{5}{|l|}{ Redox Status } \\
\hline $\operatorname{MDA}(\mu \mathrm{mol} / \mathrm{l})$ & $0.27 \pm 0.05$ & $0.40 \pm 0.05$ & $0.34 \pm 0.06$ & $0.46 \pm 0.10$ \\
\hline $\mathrm{TAS}(\mu \mathrm{mol} / \mathrm{l})$ & $394.72 \pm 51.42$ & $475.89 \pm 122.14$ & $408.03 \pm 23.62$ & $431.19 \pm 41.82$ \\
\hline MDA/TAS & $0.56 \pm 0.05$ & $0.99 \pm 0.17$ & $0.73 \pm 0.21$ & $0.94 \pm 0.18$ \\
\hline 3-NT (nmol/l) & $15.66 \pm 1.40$ & $33.37 \pm 5.46$ & $50.45 \pm 3.22$ aаa & $17.08 \pm 4.34^{\mathrm{bb}}$ \\
\hline
\end{tabular}

$\mathrm{N}$ : nephrectomy. Results are mean \pm s.e.m. of 7 rats for each group: a $-p<0.05$, aa $-p<0.01$ and aaa $-p<0.001 v s$ the control group; $\mathrm{b}-p<0.05$, bb $-p<0.01$ and bbb $-p<0.001 v s$ the CRF group.

No statistically significant changes were found between $\mathrm{CRF}$ and control group for MDA and TAS, but a significantly $(\mathrm{P}<0.05)$ higher serum concentration of $3-\mathrm{NT}$ was found. The rhEPO treatment in CRF rats $(\mathrm{CRF}+\mathrm{rhEPO}$ group) showed a trend to increased serum concentration of MDA and TAS, although no significant evidences were observed between the groups. However, a statistically significant reduction of serum 3-NT levels was found between the group of CRF with rhEPO and those without rhEPO therapy (Table 3).

\section{Real Time-PCR Gene Expression}

The kidney gene expression of the inflammatory biomarker I12 was upregulated in $\mathrm{CRF}(\mathrm{P}<0.05$, without significant changes in the group under rhEPO treatment after nephrectomy. rhEPO treatment, alone, was able to reduce II2 gene expression below the control levels (Fig. 1). Vegf gene was upregulated $(\mathrm{P}<0.05)$ in the kidney tissue from $\mathrm{CRF}$ and $\mathrm{CRF}+\mathrm{rhEPO}$ groups, in respect to the downregulation observed for the EPO group. Kidney Nos2 and Nos3 gene expression were not significantly altered in the rhEPO group $v s$ the control. However, there was a trend to higher values in the CRF group, without a consistent reduction when rhEPO was given to CRF rats (Fig. 1).

\section{DISCUSSION}

In chronic kidney disease (CKD) patients, anemia has been identified as an independent risk factor for progression of the disease, as it conditions tissue hypoxia, and, therefore, may contribute or perpetuate preexisting renal tissue injury [21]. There is some evidence suggesting that rhEPO therapy is able to retard progression of renal failure. However, there are some controversial results about this subject [22], which can be related to distinct molecular pathways and/or to EPO 

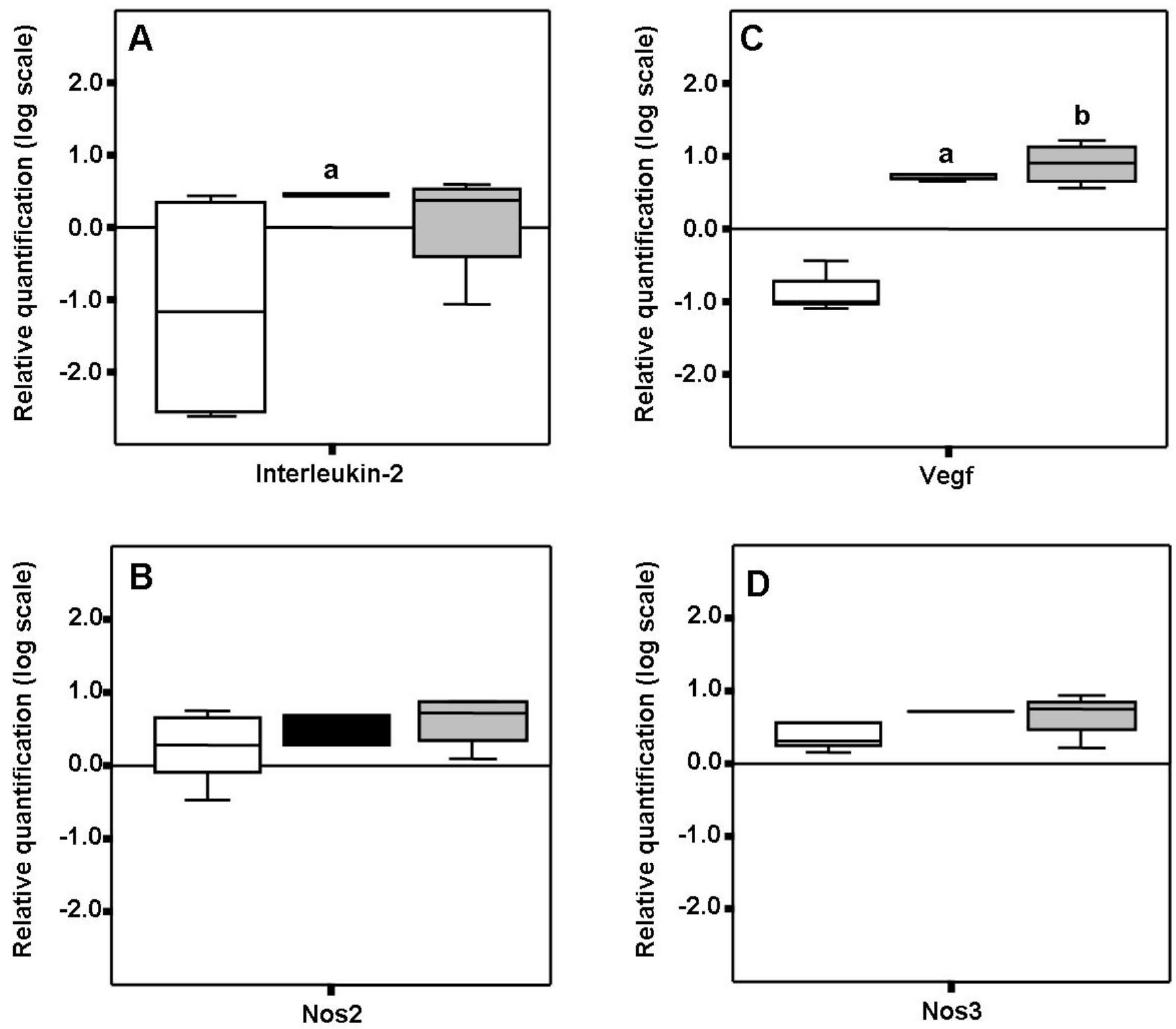

\section{$\square$ rhEPO $\square$ CRF $\square$ CRF+rhEPO}

Fig. (1). Relative gene expression quantification for Interleukin-2 (A), Vegf (B), Nos2 (C) and Nos3 (D) in rhEPO, CRF and CRF+rhEPO groups comparatively to control group (zero line). Values are expressed in logarithmic scale. $\mathbf{a}-p<0.05 v s$ the control group; $\mathbf{b}-p<0.05 v s$ the rhEPO group.

tissue receptor affinities that mediate the effect of EPO on erythropoiesis and on tissue protection.

The studies of the effect of rhEPO in non-erythroid tissues are very difficult to perform in human subjects, justifying the development of animal models. In this work, an evaluation of the effect of rhEPO on blood inflammatory and oxidative stress markers, and on a potential renoprotection, was performed, by using a rat model of moderate renal failure.

Our model of surgical partial (3/4) nephrectromy produces a moderate, but sustained stage of chronic renal failure. Indeed, we observed a significant increase in serum urea and creatinine concentrations at 3 weeks after the surgery, in CRF and CRF+rhEPO groups that remained almost constant during the following period. However, in $\mathrm{CRF}+$ rhEPO rats, a decrease in creatinine serum levels was observed after 12 weeks of rhEPO treatment, suggesting a slight recovery of renal function associated to this treatment.

Anaemia is a common complication associated with CKD. It has also a negative impact on cardiovascular system, cognitive function, exercise capacity and quality of life, resulting in a significant morbidity and mortality in these patients $[7,8]$. This anaemia is mainly determined by the rate of renal insufficiency and, therefore, by the reduction 
in the renal secretion of erythropoietin. In our CRF rats, we found a decrease in RBC count, $\mathrm{Hb}$ concentration and HTC, 3 weeks after nephrectomy, consistent with the development of anaemia secondary to renal mass reduction; moreover, the number of reticulocytes, as well as the percentage of immature reticulocytes did not increase, further supporting a failure of the erytropoietic response mechanisms, due to insufficient erythropoietin production associated to the reduction in renal tissue. However, the anaemia is notoriously transitory, as RBC count, HTC and $\mathrm{Hb}$ returned to the normal values at 9 weeks of study (data not shown) and sustained their values at 15 weeks of study, in both CRF and $\mathrm{CRF}+\mathrm{rhEPO}$ rat groups. These results suggests that the remaining kidney is able to maintain EPO production in a sufficient amount to support erythropoiesis, that seems to be slightly accelerated in CRF rats as compared to CRF rats with rhEPO treatment, as suggested by the trend towards higher values of immature reticulocytes observed in CRF rats. Moreover, we found a trend for an increased kidney weight (hypertrophy), increased serum levels of TGF- $\beta 1$ and kidney expression of Vegf markers, further suggesting an increase in renal tissue proliferation/hypertrophy, consistent with a compensated renal insufficiency. Serum levels of TGF- $\beta 1$ are significantly higher in CRF rats treated with rhEPO, suggesting that rhEPO may contribute to increase remnant kidney hypertrophy and/or have a systemic induced proliferative activity. This observation suggests a probable mechanism contributing for relative renal recovery function associated to rhEPO treatment.

Besides the anaemia secondary to renal failure, CKD patients usually develop cardiac failure that further worsens renal disease. This triad of dysfunctions, already known as cardio-renal anaemia syndrome, is responsible for the serious complications observed in these patients [23-25]. Hypertension is a well established cause of CVD, a common complication in CKD, and, therefore, an important risk factor for progression of the cardiovascular complications and mortality of CKD patients [26]. Additionally, treatment with rhEPO has also been associated with hypertension [2729]. Our results confirmed these conditions, with increased blood pressure (systolic and diastolic), together with tachycardia and heart and left ventricle hypertrophy, in both groups of CRF rats (with and without rhEPO treatment). However, the heart rate increase in the CRF rats was prevented in the group under rhEPO treatment, which might be due to a reduction of sympathetic overactivity, a common feature observed in CKD patients [30] that might result from the preventive effect of rhEPO on the development of anaemia and heart insufficiency. It seems that rhEPO promotes heart hypertrophy, thus compensating the putative insufficiency that anaemia could originate.

In CKD patients under haemodialysis, inflammation and oxidative stress are consistent findings and could play a crucial role in the pathogenesis of atherosclerosis, malnutrition and anaemia in these patients [31]. Additionally, an enhancement in these conditions has been associated with resistance to rhEPO treatment [32-34]. Our CRF rats, after 12 weeks of partial nephrectomy, showed normal blood values for the studied inflammatory markers, except TGF- $\beta 1$ that, as previously referred, may reflect an underlying proliferative recovering process of the renal tissue, which should be further confirmed by testing the gene expression or the levels produced by the kidney. However, at the kidney tissue level, CRF rats presented a higher gene expression of I12, a pro-inflammatory cytokine, suggesting that a residual inflammation still persists. Moreover, a higher Vegf gene expression was also observed, further strengthening a proliferative recovering process of the renal tissue and the need to counterbalance hypoxia at kidney level by inducing angiogenesis. Our results also showed that the rhEPO treatment did not interfere with these changes neither at blood level nor at kidney levels. However, rhEPO treatment along a CRF condition seem to gain an active role as suggested by the even higher blood values (as compared to CRF rats) of TGF- $\beta 1$; at kidney tissue it seems to play also a protective role, as suggested by the trend to lower values (though without statistical significance) for the gene expression of II2 and the higher for Vegf.

The continuous administration of rhEPO in rats did not induce erythrocytosis after 15 weeks of treatment, though some changes were observed in iron metabolism, namely a significant increase in iron storages, as showed by ferritin values. We may hypothesize that a negative feedback mechanism may develop, reducing the mobilization of iron from the storage pool, in order to maintain normal values of circulating erythrocytes, reducing, therefore, the risk associated with a high blood viscosity [35]. We believe this can not be due to the development of anti-rhEPO antibodies, as this is usually associated to a severe anemia [35]. Actually, in CRF rats treated also with rhEPO, the same changes were observed after 15 weeks of treatment, though in a reduced way that is probably due to the reduced contribution of endogenous EPO. The group of rats with only CRF, when compared to control presented higher values of ferritin (though about five times lower than the values presented by CRF+rhEPO group), lower values transferrin and a trend to lower values of seric iron. These changes, usually described for inflammatory processes, may reflect the low grade inflammation observed in these patients.

In our CRF rats, the redox state seems to be unaltered (MDA/TAS ratio was unchanged), which might be due to a proper compensation, to remove ROS by antioxidants, eventually resulting from the moderate renal failure condition. However, there was an increase in serum 3-NT value, which is a marker of peroxynitrite generation, and, thus, might hypothetically reflect an increased superoxide formation and, thus, a reduced NO availability, since this dangerous oxidant is formed by the combination of both. Furthermore, the trend to increased gene expression of both Nos isoforms in the remnant kidney of CRF, might suggests an increment of $\mathrm{NO}$, thus contributing to peroxynitrite formation when superoxide is abundant. On the other hand, the trend to increment in kidney gene expression of the inducible Nos isoforms might also be viewed as an additional confirmation of the existence of a kidney inflammatory response in this model of moderate renal failure. The putative importance of this response and the character of the results now obtained deserve further efforts in order to clarify both the inflammatory response and the involvement of $\mathrm{NO}$ in this profile. The treatment with rhEPO in the CRF rats has decreased serum 3-NT levels, suggesting an antioxidative effect of erythropoietin, despite no correction of Nos overexpression. 
In conclusion, our data are consistent with a model of moderate, but sustained, degree of chronic renal failure, with development of moderate and corrected anaemia and hypertension. This was accompanied by low grade inflammatory and pro-oxidative processes at blood level and, at kidney tissue level a proliferative/recovering stimuli, which might be viewed as a compensatory phenomenon. In this model, rhEPO treatment was able to partially improve renal function, to correct anaemia, and to have a proliferative and antioxidant action. Since the pathophysiological modifications underlying CRF seems to be dependent on the insufficiency degree, this study suggests that rhEPO therapy might be recommended in moderate CRF stages in order to efficiently correct not only the anaemia but also the underlying deleterious mechanisms, thus demonstrating a pleiotrophic renoprotective action.

\section{REFERENCES}

[1] Miyoshi, I.; Saito, T.; Bandobashi, K.; Ohtsuki, Y.; Taguchi, H. Concomitant deposition of aluminum and iron in bone marrow trabeculae. Intern. Med., 2006, 45, 117-118.

[2] Medina, A.; Ellis, C.; Levitt, M.D. Use of alveolar carbon monoxide measurements to assess red blood cell survival in hemodialysis patients. Am. J. Hematol., 1994, 46, 91-94.

[3] Pisoni, R.L.; Bragg-Gresham, J.L.; Young, E.W.; Akizawa, T.; Asano, Y.; Locatelli, F.; Bommer, J.; Cruz, J.M.; Kerr, P.J.; Mendelssohn, D.C.; Held, P.J.; Port, F.K. Anemia management and outcomes from 12 countries in the Dialysis Outcomes and Practice Patterns Study (DOPPS). Am. J. Kidney Dis., 2004, 44, 94-111.

[4] Bárány, P. Inflammation, serum C-reactive protein, and erythropoietin resistance. Nephrol. Dial. Transplant., 2001, 16, 224-227.

[5] Locatelli, F.; Pisoni, R.L.; Combe, C.; Bommer, J.; Andreucci, V.E.; Piera, L.; Greenwood, R.; Feldman, H.I.; Port, F.K.; Held, P.J. Anaemia in haemodialysis patients of five European countries: association with morbidity and mortality in the Dialysis Outcomes and Practice Patterns Study (DOPPS). Nephrol. Dial. Transplant., 2004, 19, 121-132.

[6] Smrzova, J.; Balla, J.; Bárány, P. Inflammation and resistance to erythropoiesis-stimulating agents--what do we know and what needs to be clarified? Nephrol. Dial. Transplant., 2005, 20, viii2-7.

[7] Foley, R.N.; Parfrey, P.S.; Harnett, J.D.; Kent, G.M.; Murray, D.C.; Barre, P.E. The impact of anemia on cardiomyopathy morbidity and mortality in end-stage renal disease. Am. J. Kidney Dis., 1996, 28, 5361.

[8] Locatelli, F.; Conte, F.; Marcelli, D. The impact of hematocrit levels and erythropoietin treatment on overall and cardiovascular mortality and morbidity - the experience of the Lombardy dialysis registry. Nephrol. Dial. Transplant., 1998, 13, 1642-1644.

[9] Bogoyevitch, M.A. An update on the cardiac effects of erythopoietin cardioprotetion by erythropoietin and the lessons learnt from studies in neuroprotection. Cardiovasc. Res., 2004, 63, 208-216.

[10] Bahlmann, F.H.; De Groot, K.; Haller, H.; Fliser, D. Erythropoetin - is it more than correcting anemia? Nephrol. Dial. Transplant., 2004, 19, 20-22.

[11] Brines, M.; Cerami, A. Emerging biological roles for erythropoietin in the nervous system. Nat. Rev. Neurosci., 2005, 6, 484-494.

[12] Dame, C.; Bartmann, P.; Wolber, E.; Fahnenstich, H.; Hofmann, D.; Fandrey, J. Erythropoietin gene expression in different areas of the developing human central nervous system. Dev. Brain. Res., 2000, 125, 69-74.

[13] Westenfelder, C.; Biddle, D.L.; Baranowski, R.L. Human, rat, and mouse kidney cells express functional erythropoietin receptors. Kidney Int., 1999, 55, 808-820.

[14] Bagnis, C.; Beaufils, H.; Jacquiud, C.; Adabra, Y.; Jouanneau, C.; Le Nahour, G.; Jaudon, M.C.; Bourbouze, R.; Jacobs, C.; Deray, G.
Erythropoietin enhances recovery after cisplatin-induced acute renal failure in the rat. Nephrol. Dial.Transplant., 2001, 16, 932-938.

[15] Yang, C.W.; Li, C.; Jung, J.Y.; Shin, S.J.; Choi, B.S.; Lim, S.W.; Sun, B.K.; Kim, Y.S.; Kim, J.; Chang, Y.S.; Bang, B. Preconditioning with erythropoietin protects against subsequent ischemia-reperfusion injury in rat kidney. FASEB J., 2003, 17, 1754-1755.

[16] Abdelrahman, M.; Sharples, E.J.; McDonald, M.C.; Collin, M.; Patel, N.S.; Yaqoob, M.M.; Thiemermann, C. Erythropoietin attenuates the tissue injury associated with hemmorrhagic shock and myocardial ischemia. Shock, 2004, 22, 63-69.

[17] Estepa, V.; Ródenas, S.M.; Martín, M.C. Optimización de un método para la determinación de la peroxidación lipídica en suero humano. Anal. Real. Acad. Farm., 2001, 67, 1-17.

[18] Benzie, I.F.F.; Strain, J.J. The Ferric Reducing Ability of plasma (FRAP) as a measure of "antioxidant power": the FRAP assay. Anal. Biochem., 1996, 239, 70-76.

[19] Vandesompele, J.; De Preter, K.; Pattyn, F.; Poppe, B.; Van Roy, N.; De Paepe, A.; Speleman, F. Accurate normalization of real-time quantitative RT-PCR data by geometric averaging of multiple internal control genes. Genome Biol., 2002, 3, RESEARCH0034.

[20] Livak, K.J.; Schmittgen, T.D. Analysis of relative gene expression data using real-time quantitative PCR and the $2^{-\Delta \Delta C T}$ method. Methods, 2001, $25,402-408$.

[21] Fliser, D.; Bahlmann, F.H.; Haller, H. EPO: renoprotetion beyond anemia correction. Pediatr. Nephrol., 2006, 21, 1785-1789.

[22] Sharples, E.J.; Thiemermann, C.; Yaqoob, M.M. Novel applications of recombinant erythropoietin. Curr. Opin. Pharmacol., 2006, 6, 184-189. Parmar, M.S. Chronic renal disease. BMJ, 2002, 325, 85-90.

[24] Silverberg, D.; Wexler, D.; Blum, M.; Wollman, Y.; Iaina, A. The cardio-renal anaemia syndrome: does it exist? Nephrol. Dial. Transplant., 2003, 18, viii7-viii12.

[25] Wexler, D.; Silverberg, D.; Blum, M.; Sheps, D.; Keren, G.; Wollman, Y.; Schwartz, D.; Iaina, A. Anaemia as a contributer to morbidity and mortality in congestive heart failure. Nephrol. Dial. Transplant., 2005, 20, viil1-vii15.

[26] Fernandez-Fresnedo, G.; Rodrigo, E.; de Francisco, A.L.; de Castro, S.S.; Castaneda, O.; Arias, M. Role of pulse pressure on cardiovascular risk in chronic kidney disease patients. J. Am. Soc. Nephrol., 2006, 17, S246-S249.

[27] Vaziri, N.D. Mechanism of erythropoietin-induced hypertension. Am. J Kidney Dis., 1999, 33, 821-828.

[28] Smith, K.J.; Bleyer, A.J.; Little, W.C.; Sane, D.C. The cardiovascular effects of erythropoietin. Cardiovasc. Res., 2003, 59, 538-548.

[29] Jie, K.E.; Verhaar, M.C.; Cramer, M.J.; van der Putten, K.; Gaillard, C.A.; Doevendans, P.A.; Koomans, H.A.; Joles, J.A.; Braam, B. Erythropoietin and the cardiorenal syndrome: cellular mechanisms on the cardiorenal connectors. Am. J. Physiol. Renal Physiol., 2006, 291, F933-F944.

[30] Koomans, H.A.; Blankestijn, P.J.; Joles, J.A. Sympathetic hyperactivity in chronic renal failure: a wake-up call. J. Am. Soc. Nephrol., 2004, 15, 524-537.

[31] Neumann, J.; Ligtenberg, G.; Klein, I.H.; Boer, P.; Oey, P.L. Koomans, H.A.; Blankestijn, P.J. Response to sympathetic hyperactivity in hypertensive chronic kidney disease patients is reduced during standard treatment. Hypertension, 2007, 49, 506-510.

[32] Spittle, M.A.; Hoenich, N.A.; Handelman, G.J.; Adhikarla, R.; Homel, P.; Levin, N.W. Oxidative stress and inflammation in hemodialysis patients. Am. J. Kidney Dis., 2001, 38, 408-1413.

[33] Pupim, L.B.; Himmelfarb, J.; McMonagle, E.; Shyr, Y.; Ikizler, T.A. Influence of initiation of maintenance hemodialysis on biomarkers of inflammation and oxidative stress. Kidney Int., 2004, 65, 2371-2379.

[34] Smrzova, J.; Balla, J.; Bárány, P. Inflammation and resistance to erythropoiesis-stimulating agents--what do we know and what needs to be clarified? Nephrol. Dial. Transplant., 2005, 20 ,viii2-7.

[35] Manolis, A.S.; Tzeis, S.; Triantafyllou, K.; Michaelidis, J.; Pyrros, I.; Sakellaris, N.; Kranidis, A.; Melita, H. Erythropoietin in heart failure and other cardiovascular diseases: hematopoietic and pleiotropic effects. Curr. Drug Targets Cardiovasc. Haematol. Disord., 2005 , 5, 355-375. 